\title{
The Characteristics of Professional Learning Community of Primary Schools in Udon Thani Province
}

\author{
Somkid Sroinam \\ Department of Educational Administration \\ Udon Thani Rajabhat University \\ Thailand
}

\begin{abstract}
Professional Learning Community (PLC) is a new trend for teacher development in Thailand. In order to learn more about PLC, the purposes of this research were to study and compare the characteristics of professional learning community of primary schools in Udon Thani province perceived by school administrators and teachers classified by work experiences and school sizes. The participants consisted of 265 school administrators and 367 teachers selected by two-stage random sampling. The5-rating scale questionnaire with the reliability coefficient of 0.96 was employed for data collecting. The data we reanalyzed by using Statistical Package for the Social Sciences (SPSS) for percentage, mean, standard deviation, t-test, one-way analysis of variance and paired different test by Scheffe's method. The results led to understand the characteristics of professional learning community in primary schools and the research application was discussed.
\end{abstract}

Keywords: Professional Learning Community, PLC, Primary Schools

\section{Introduction}

The problem of teacher production institute that is based on the capacity and capability of each institution depends on needs of learners who focus on the degree rather than knowledge and performance. The production of teachers in commercial production has affected the quality of graduates who lack of skills, knowledge, capacity and competency according to professional standards. In addition, the problem of teacher's personnel management has had impact on the potential and performance of the Thai teachers. The teachers have lacked of the depth in the content of the teaching and have also lacked of skills and competencies in accordance with professional standards. This has affected the quality and efficiency of instruction. (Office of the Education Council, 2017)

Professional Learning Community (PLC) is a continuous process that teachers and educators work together in the cycle of common questioning and learning action research to achieve better learning outcomes of students (Panich, 2016). This corresponds to Chaichaowarat (2017) stated that PLC was the development of students learning together, setting the learning goals of the learner and examining, reflecting on both personal performance and overall outcome through the learning process, criticism and teamwork cooperation focusing on promoting a holistic learning process. Furthermore, DuFour (2002) indicated that the collaboration in schools to find best practices for developing learning process in the classrooms focusing on students' learning continuously was a professional learning community (PLC) by collaboration of teachers, administrators, parents and students.

21st Century Education is the most necessary way for everyone to change their way of learning to keep pace with the changing world. Development of the community or country to progress quickly and very well depends on several important factors. However, among those important factors it is generally accepted that human factor is a very important factor. Any community or country cannot develop a human; it cannot be good to develop other factors. It is accepted that the key tools used to develop "people" to the development dimension in various areas is "education" (Sararattana, 2010). The concept of learning in the 21st century is the learning society, the learning organization, and the lifelong learning (Office of the Education Council, 2008) Development of teacher professional competency and 21st-century skills of learners that focus on high-level thinking and cooperation can be developed using professional learning community process (PLC). This is due to the fact that teachers have more professional performance (Theparee, 2014). In addition, Saisanitsareekul (2014) said that the effective way to improve the quality of education by upgrading the whole system and developing the characteristics of learners to be equivalent to universal. 
Strengthening the future learning skills should building a professional learning community (PLC) as part of a school-based management in order to progress teachers having awareness of the importance of instructional design, teaching and learning assessment to be consistent to the students' needs and society needs. Furthermore, Jessie (2007) stated that education management needs to meet the school's needs truly bythe parent's collaboration with the three principles that were focusing on learning, cooperation culture and focusing on results. A professional learning community (PLC) is the best way to improve and develop the students' performance.

Udon Thani Rajabhat University has played an important role in the development of Udon Thani and neighboring provinces for local development with the mission of statute 7 . This specifies the university has been a higher education institution for local development, strengthening the local intellectual power, refreshing the learning power, raising the local wisdom, creating a new era of prosperity and stability. Moreover, the university has to participate in management natural resources and environment sustainably. The university purposes are to provide academic services to the society, improve and transfer technology to preserve the arts and culture and also produce teachers and promote teachers academic standing. One important mission is strengthening the teacher profession, promoting of teachers and producing new trend of teacher development to be quality and consistent with the plan to develop teachers and educational personnel (Udon Thani Rajabhat University, 2017).

According to the above importance, this research tried to study the characteristics of professional learning community of primary schools in Udon Thani province perceived by school administrators and teachers. In addition, this study compared the characteristics of professional learning community of primary schools in Udon Thani province perceived by school administrators and teachers classified by work experiences and school sizes. This may lead to understand the characteristics of professional learning community in schools and it is the starting point to plan for developing professional learning community of school administrators and teachers in Udon Thani province.

\section{Method}

\subsection{Participants}

The participants in this research consisted of 265 teachers and 367 administrators of primary schools in Udon Thani province. The sample size was employed by Krejcie and Morgan table that calculated the sample by proportion of teachers and administrators in each school. Then, stratified random sampling and simple random sampling were applied.

\subsection{Measures}

The instrument used in this study was a questionnaire comprised 2 parts consisted of background data of the participants and the characteristics of professional learning community of schools.

\subsubsection{Part 1}

It was the list to inquire general data of the participants that consisted of work position, school size and work experience.

\subsubsection{Part 2}

It composed of the rating scale questions that was created along Hordconcept (Hord, 1997)to inquire the characteristics of professional learning community of schools with the reliability of 0.96 . The characteristics of professional learning community consisted of 1) value and shared vision 2) support and leadership 3) learning and sharing benefit 4) learning exchange and 5) conditions of support

\subsection{Procedure and design}

This study was a survey research collecting data by a questionnaire. The data was collected by mail after the researcher has sentthe letters to the target schools. The questionnaires were proposed to the school administrators and teachers and defined the return date.

2.4 Statistical analysis The data was analyzed by using Statistical Package for the Social Sciences: SPSS. The descriptive statistics was applied for frequency, percentage, mean, standard deviation. Independent sample t-test was applied to compare the characteristics of professional learning community between schools administrators and teachers. 
Moreover, one-way ANOVA analysis was employed to compare the characteristics of professional learning community classified by work experiences and school sizes with Scheffe's method.

\section{Results}

3.1 The characteristics of professional learning community of primary schools in UdonThani province perceived by school administrators and teachers were rated at high level in overall and each aspect. In the comparison found that in overall and each aspects were statistical different at .01level of significance as Table 1.

Table 1.Thecomparisonof the characteristics of professional learning community of primary schools in UdonThani province perceived by school administrators and teachers

\begin{tabular}{llllll}
\hline \multirow{2}{*}{$\begin{array}{l}\text { The characteristics of professional } \\
\text { learning community }\end{array}$} & \multicolumn{4}{l}{$\begin{array}{l}\text { School } \\
\text { Administrators }\end{array}$} & \multirow{2}{*}{ Teachers } \\
\cline { 2 - 5 } & Mean & S.D. & Mean & S.D. & \\
\hline 1. value and shared vision & 3.94 & 0.42 & 3.85 & 0.46 & $3.72^{* *}$ \\
2. support and leadership & 3.97 & 0.43 & 3.83 & 0.47 & $3.73^{* *}$ \\
3. learning and sharing benefit & 4.00 & 0.43 & 3.85 & 0.46 & $3.77^{* *}$ \\
4. learning exchange & 4.04 & 0.40 & 3.84 & 0.46 & $5.55^{* *}$ \\
5. conditions of support & 4.00 & 0.41 & 3.59 & 0.23 & $14.17^{* *}$ \\
\hline Overall & 4.00 & 0.41 & 3.79 & 0.38 & $6.44^{* *}$ \\
\hline
\end{tabular}

3.2 The characteristics of professional learning community of primary schools in UdonThani province perceived by school administrators classified by work experiences found that three groups of work experiences were rated at high level in overall and each aspect. The characteristics of professional learning community of schools perceived by school administrators classified by school sizes found that three school sizes were rated at high level in overall and each aspect. In the comparison, the characteristics of professional learning community of schools perceived by school administrators classified by work experiences found that in overall and each aspect were not different. In the comparison, classified by school sizes found that in overall and each aspects were not different except the conditions of supporting aspect was statistical different at .01level of significance as Table 2-3.

Table 2.Thecomparisonof the characteristics of professional learning community of primary schools in UdonThani province perceived by school administrators classified by work experiences

\begin{tabular}{|c|c|c|c|c|c|c|c|}
\hline \multirow{3}{*}{$\begin{array}{l}\text { The characteristics of } \\
\text { professional } \\
\text { learning community }\end{array}$} & \multicolumn{6}{|c|}{ work experiences } & \multirow{3}{*}{$\mathrm{F}$} \\
\hline & \multicolumn{2}{|c|}{$\begin{array}{l}\text { Less than } 5 \\
\text { years }\end{array}$} & \multicolumn{2}{|c|}{$5-10$ years } & \multicolumn{2}{|c|}{$\begin{array}{l}\text { More than } 10 \\
\text { years }\end{array}$} & \\
\hline & Mean & S.D. & Mean & S.D. & Mean & S.D. & \\
\hline 1. value and shared vision & 4.02 & 0.42 & 3.94 & 0.40 & 4.00 & 0.43 & 0.64 \\
\hline 2. support and leadership & 4.00 & 0.43 & 3.93 & 0.41 & 3.98 & 0.44 & 0.40 \\
\hline $\begin{array}{l}\text { 3. learning and sharing } \\
\text { benefit }\end{array}$ & 4.02 & 0.42 & 3.95 & 0.39 & 4.00 & 0.44 & 0.48 \\
\hline 4. learning exchange & 4.08 & 0.45 & 3.98 & 0.45 & 4.06 & 0.46 & 0.89 \\
\hline 5. conditions of support & 4.00 & 0.43 & 3.99 & 0.42 & 4.01 & 0.44 & 0.90 \\
\hline Overall & 4.03 & 0.43 & 3.96 & 0.38 & 4.01 & 0.43 & 0.50 \\
\hline
\end{tabular}

Table 3.Thecomparisonof the characteristics of professional learning community of primary schools in UdonThani province perceived by school administrators classified by school sizes

\begin{tabular}{|c|c|c|c|c|c|c|c|}
\hline \multirow{3}{*}{$\begin{array}{l}\text { The characteristics of } \\
\text { professional } \\
\text { learning community }\end{array}$} & \multicolumn{6}{|c|}{ school sizes } & \multirow{3}{*}{$\mathrm{F}$} \\
\hline & \multicolumn{2}{|l|}{ small } & \multicolumn{2}{|c|}{ medium } & \multicolumn{2}{|l|}{ large } & \\
\hline & Mean & S.D. & Mean & S.D. & Mean & S.D. & \\
\hline 1. value and shared vision & 4.01 & 0.44 & 3.83 & 0.34 & 4.01 & 0.47 & 1.06 \\
\hline 2. support and leadership & 3.99 & 0.46 & 3.91 & 0.35 & 4.02 & 0.46 & 1.45 \\
\hline $\begin{array}{l}\text { 3. learning and sharing } \\
\text { benefit }\end{array}$ & 4.02 & 0.45 & 3.94 & 0.35 & 4.04 & 0.47 & 1.38 \\
\hline 4. learning exchange & 4.08 & 0.49 & 4.00 & 0.37 & 4.01 & 0.52 & 1.42 \\
\hline 5. conditions of support & 3.99 & 0.45 & 3.90 & 0.35 & 4.21 & 0.45 & $8.31^{* *}$ \\
\hline Overall & 4.01 & 0.44 & 3.94 & 0.35 & 4.06 & 0.42 & 1.46 \\
\hline
\end{tabular}


3.3 The characteristics of professional learning community of primary schools in UdonThani province perceived by teachers classified by work experiences found that three groups of work experiences were rated at high level in overall and each aspect. The characteristics of professional learning community of schools perceived by teachers classified by school sizes found that three school sizes were rated at high level in overall and each aspect. The comparison, the characteristics of professional learning community of schools perceived by school administrators classified by work experiences found that in overall and each aspect were not different. In the comparison, classified by school sizes found that in overall and each aspects were not different except the supportive conditions aspect was statistical different at .01level of significanceas Table 4-5.

Table 4.Thecomparisonof the characteristics of professional learning community of primary schools in UdonThani province perceived by teachers classified by work experiences

\begin{tabular}{|c|c|c|c|c|c|c|c|}
\hline \multirow{3}{*}{$\begin{array}{l}\text { The characteristics of } \\
\text { professional } \\
\text { learning community }\end{array}$} & \multicolumn{6}{|c|}{ work experiences } & \multirow{3}{*}{$\mathrm{F}$} \\
\hline & \multicolumn{2}{|c|}{$\begin{array}{l}\text { Less than } 5 \\
\text { years }\end{array}$} & \multicolumn{2}{|c|}{$5-10$ years } & \multicolumn{2}{|c|}{$\begin{array}{l}\text { More than } 10 \\
\text { years }\end{array}$} & \\
\hline & Mean & S.D. & Mean & S.D. & Mean & S.D. & \\
\hline 1. value and shared vision & 3.99 & 0.59 & 3.93 & 0.55 & 3.84 & 0.44 & 1.41 \\
\hline 2. support and leadership & 3.98 & 0.61 & 3.90 & 0.54 & 3.82 & 0.46 & 1.18 \\
\hline $\begin{array}{l}\text { 3. learning and sharing } \\
\text { benefit }\end{array}$ & 4.08 & 0.61 & 3.93 & 0.55 & 3.86 & 0.44 & 2.67 \\
\hline 4. learning exchange & 3.99 & 0.59 & 3.94 & 0.55 & 3.83 & 0.44 & 1.65 \\
\hline 5. conditions of support & 3.51 & 0.07 & 3.61 & 0.45 & 3.59 & 0.20 & 0.94 \\
\hline Overall & 3.91 & 0.46 & 3.86 & 0.49 & 3.78 & 0.36 & 1.43 \\
\hline
\end{tabular}

Table 5.Thecomparisonof the characteristics of professional learning community of primary schools in UdonThani province perceived by teachers classified by school sizes

\begin{tabular}{|c|c|c|c|c|c|c|c|}
\hline \multirow{3}{*}{$\begin{array}{l}\text { The characteristics of } \\
\text { professional } \\
\text { learning community }\end{array}$} & \multicolumn{6}{|c|}{ school sizes } & \multirow{3}{*}{$\mathrm{F}$} \\
\hline & \multicolumn{2}{|l|}{ small } & \multicolumn{2}{|c|}{ medium } & \multicolumn{2}{|l|}{ large } & \\
\hline & Mean & S.D. & Mean & S.D. & Mean & S.D. & \\
\hline 1. value and shared vision & 3.82 & 0.48 & 3.87 & 0.48 & 3.84 & 0.42 & 0.38 \\
\hline 2. support and leadership & 3.81 & 0.49 & 3.87 & 0.49 & 3.79 & 0.43 & 1.20 \\
\hline $\begin{array}{l}\text { 3. learning and sharing } \\
\text { benefit }\end{array}$ & 3.84 & 0.49 & 3.87 & 0.48 & 3.84 & 0.42 & 0.22 \\
\hline 4. learning exchange & 3.81 & 0.49 & 3.85 & 0.48 & 3.84 & 0.40 & 0.29 \\
\hline 5. conditions of support & 3.56 & 0.15 & 3.55 & 0.23 & 4.65 & 0.25 & $8.14 * *$ \\
\hline Overall & 3.77 & 0.38 & 3.81 & 0.39 & 3.80 & 0.37 & 0.22 \\
\hline
\end{tabular}

\section{Discussion and Conclusion}

4.1 The characteristics of professional learning community of primary schools in UdonThani province perceived by school administrators and teachers were rated at high level in overall and each aspect. In the comparison found that in overall and each aspects were statistical different at .01level of significance. This may be due to the fact that school administrators and teachers have different roles in the workplace. The organization's management structure includes academic work, budget, human resources management and general administration. The role of teachers should be set to work in all four aspects to ensure consistency in quality. However, the school administrators must also coordinate with school administrators in the network schools and the educational service area office. Meanwhile, the teachers have the main task to organize learning for learners in the responsible subject. As a result, the teachers and administrators realized that the characteristics of professional learning community in school were different. The results of this research are consistent with finding of Boonraksa (2010) studied the professional learning community in schools under the local government organization in Loei Province found that professional learning community in administrators and teachers opinions was at the high level in all aspects. This is also consistent with Intanam, Wongwanich and Lawthong (2012) studying on the development of professional learning community models. The teacher's perceptions in the context of Thai education found that the pattern of professional learning community had two levels: individual and organizational levels. 
There were 5 factors in the professional learning community. These factors have different weight values. In addition, the research found that the emergence of a professional learning community at the organizational level is greater than the inclusion of professional learning community of individual all factors.

4.2 The characteristics of professional learning community of primary schools in UdonThani province perceived by school administrators classified by work experiences found that three groups of work experiences were rated at high level in overall and each aspect. The characteristics of professional learning community of schools perceived by school administrators classified by school sizes found that three school sizes were rated at high level in overall and each aspect. In the comparison, the characteristics of professional learning community of schools perceived by school administrators classified by work experiences found that in overall and each aspect were not different. This may be the concept of professional learning community is a relatively new concept for schools. Teachers who involved in the promotion and management of learning for learners have the same time experience in professional learning community concept. In the same way, school administrators with more than 10 years of experience have recognized the professional learning community as well as the new administrators.

In the comparison, classified by school sizes found that in overall and each aspect were not different except the supportive conditions aspect was statistical different at .01level of significance. This perhaps due to the budget allocation of the school administration comes from the subsidy which is based on the number of students so the small and the medium school administrators have different administrative budgets to support school activities. This result corresponded to Eastwood and Louis (1992) which stated that the provision of structural support including the collaborative atmosphere that was the most important factor to development and improve school efficiency. Furthermore, Hord(1997) pointed out that there were two types of support structures in the professional learning community consisted of the conditions of support and human relations. The conditions of support were discussed in terms of time, communication, school size, sufficiency of staff and team development process. The condition of support was the key to the survival and growth of the learning community.

4.3 The characteristics of professional learning community of primary schools in UdonThani province perceived by teachers classified by work experiences found that three groups of work experiences were rated at high level in overall and each aspect. In the comparison, the characteristics of professional learning community of schools perceived by teachers classified by work experiences found that in overall and each aspect were not different. This may be most teachers in the school have more than 10years of experience. They can apply learning management experience for solving problem and suggest the less experienced teachers by internal supervision. On the other hand, less experienced teachers have been educated new knowledge, new technology, and innovations lead to mutual learning. As a result, there is no difference in the perception of professional learning community. This is consistent with the main view of professional learning community that is collaborative learning in the case of teachers work together for performance assessment, students' needs, students' interests and skills (McREL, 2003). Moreover, teachers exchange and talk about teaching, observe each other, work for new experience together to develop strengths and relationships among teachers (Hord, 1997).

The characteristics of professional learning community of schools perceived by teachers classified by school sizes found that three school sizes were rated at high level in overall and each aspect. In the comparison, classified by school sizes found that in overall and each aspects were not different except the supportive conditions aspect was statistical different at .01 level of significance. This may be due to the fact that small and medium schools have a lower number of teachers resulting in a large number of school workloads. In addition, it causes a problem with the time management in the classroom, the lack of budget to support the creation of instructional media. This research is consistent with Stoll and Louis (2007) conducted research on community learning networks. It was found that all schools with school-based management are characterized by a learning community naturally. The condition of support has an influence on the learning community, which the context of the school affected to the conditions of support. Furthermore, it was also found that the schools where are far from the urban or higher education institutions disadvantaged of being a learning community.

\section{Recommendations}

The further research should study factors that affect professional learning community of schools to seek factors to predict professional learning community of schools and support professional learning community building. Moreover, the research should develop the ways of building professional learning community to guide schools create professional learning community clearly. 


\section{References}

Boonraksa, T. (2010).Factors influencing the learning community of the schools under the Local Administrative Organization in Loei Province.Unpublished dissertation in Educational Administration of LoeiRajabhat University.

Chaichaowarat, R. (2017). The concept of professional learning community for teacher professional development.Journal of Education of SurinRajabhat University. 10 (1) 34-46.

Dufour, R. (2002). Time, Perspective and Priorities.In Eaker, R., Dufour, R. \&Burnette, R. (2002). Getting Started: Reculturing Schools to Become Professional Learning Communities (Solutions). National Educational Service, Bloomington,Indiana.

Eastwood, K., \& Louis, K. (1992). Restructuring that lasts: Managing the performance dip. Journal of School Leadership. 2(2), 213-224.

Hord, S. M. (1997). Professional learning communities: Communities of continuous inquiry and improvement. Austin, Texas: Southwest Educational Development Lab.

Intanam N., Wongwanich S., Lawthong N. (2012). Development of a model for building professional learning communities in school: teachers' perspectives in Thai Educational context. In G.

Almerico (Ed.), Journal of case of studies in education(pp. 1-11.) Florida: Academic and Business Research Institute.

Jessie, L.G. (2007). The Elements of a Professional Learning Community: Professional learning communities will change how you and your staff view learning. Leadership Compass, 5(2), 1-3.

McREL. (2003). Sustaining school improvement: Professional learning community. Retrieved May 10, 2012, from http://www.mcrel.org/pdf/leadershiporganizationdevelopment/5031TG_proflrncommfolio.pdfOffice of the Education Council. (2017). National Education Plan B.E. 2560-2579. Bangkok: Prikwaan Graphic.

Panich, W. (2016). Entertainment of teachers lives to the learning community. Bangkok: SR PrintingMass Product.

Saisanitsareekul, M. (2014).The School Management Strategy for the Professional Learning Community of Secondary Schools in Benjaburapha Campus, Bangkok.Unpublished dissertation inEducational Administration, Department of Policy Management and Educational Leadership,Faculty of Education, Chulalongkorn University.

Sararattana, W. (2010).School director. 7th ed. Khonkaen: Klangnanawittaya.

Stoll, L., \& Louis, K. S. (2007). Professional learning communities: Elaborating new approaches. In Stoll, L., \& Louis, K. S. (Eds.), Professional learning communities: Divergence, depth, anddilemmas. Berkshire, England: Open University Press.

Theparee, P. (2014). Development of a community-based learning model for elementary schoolteachers. Unpublished dissertation in Research and Curriculum Development Srinakharinwirot University.

UdonThaniRajabhat University.(2017). Information of UdonThaniRajabhat University. Retrieved January 13, 2017 fromhttp://www.udru.ac.th/index.php/about-udru/udru-data/udruhistory.html. 